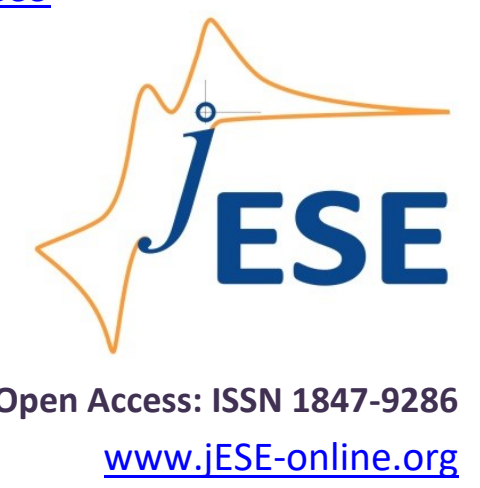

Original scientific paper

\title{
Modeling the performance of direct carbon solid oxide fuel cell - anode supported configuration
}

\author{
Sanjeev Raj, Sakthi Gnanasundaram and Balaji Krishnamurthy $\bowtie$ \\ Department of Chemical Engineering, BITS Pilani, Hyderabad 500078, India \\ Corresponding author: ${ }^{\circledR}$ balaji.krishb1@gmail.com
}

Received: November 17, 2020; Revised: January 26, 2021; Accepted: January 26, 2021

\begin{abstract}
A mathematical model is developed to study the performance of a direct carbon solid oxide fuel cell system (DC-SOFC). Simulation results indicate that in the anode supported configuration, anode design parameters (porosity, tortuosity and anode thickness) play very important role in the performance of DC-SOFC, presented as the polarization curve. The effect of $\mathrm{Ag}$ content in anode electrode is found to play a significant role in the performance of the DC-SOFC. The effect of operating parameters, namely pressure and temperature, on the overpotentials (concentration, activation and ohmic) are studied. The concentration profiles of gases $\left(\mathrm{CO}_{2}\right.$ and $\left.\mathrm{CO}\right)$ as a function of operating current density across the anode electrode is studied. Model results are compared with experimental data and found to compare well.
\end{abstract}

\section{Keywords}

Overpotential, activation, direct carbon, anode design parameters, current, potential

\section{Introduction}

Direct carbon solid oxide fuel cells (DC-SOFCs) have received a lot of attention in the recent years. In DC-SOFC, solid carbon is placed in the anode chamber and chemically oxidized by $\mathrm{CO}_{2}$ gas to form CO. The carbon monoxide then moves to the anode triple phase boundary (TPB) where it reacts to produce $\mathrm{CO}_{2}$ [1]. In the case of anode supported configuration, the thickness of the anode dominates, while in the electrolyte supported configuration, the thickness of the electrolyte dominates. Xu et al. [1] have shown that the anode supported DC-SOFC offers a much better performance than electrolyte supported DC-SOFC, owing to the reduced ohmic loss and only slightly increased concentration loss.

Very little modeling work exists in the sphere of DC-SOFC. Xu et al. [1] have published a paper studying the effect of the distance between carbon and anode on the performance of DC-SOFC. The authors also compare the performance of anode supported DC-SOFC and electrolyte supported DC- 
SOFC. In another paper [2], these authors have also studied the effect of applied voltage and operating temperature on the performance of DC-SOFC. Yang et al. [3] have developed a mathematical model to study the performance of a direct carbon solid oxide fuel cell. The authors postulated that a higher operating temperature of the fuel cell and a smaller distance between the anode and carbon enhance the performance of DC-SOFC. These researchers [4] have also developed a mathematical model to study the performance of DC-SOFC by adding water by carbon gasification in DC-SOFC. Zhang et al. [5] have evaluated the effect of operating parameters on DC-SOFC performance. Bai et al. [6] have assembled and tested a direct carbon solid oxide fuel cell stack and achieved significant peak power density. Gür et al. [7] have experimentally verified the reaction mechanism of DC-SOFC by comparing its performance with SOFC running on pure CO. Alexander et al. [8] have proposed a steam carbon air fuel cell and was able to achieve efficiency of $78 \%$ for hydrogen and electricity co-generation. Sandip Das [9] has used the dusty gas model to develop the analytical expression for the concentration overpotential of DC-SOFC. In our previous work [10], the variation of concentration profiles of $\mathrm{CO}$ and $\mathrm{CO}_{2}$ across the anode electrode was studied as a function of design parameters of the cathode.

In order to contribute to the already existing work in understanding the performance of DC-SOFC, the performance and operating overpotentials of DC-SOFC as a function of anode design parameters have thoroughly been studied in the present paper.

\section{Modeling}

The schematic of the anode supported DC-SOFC is shown in Figure 1.

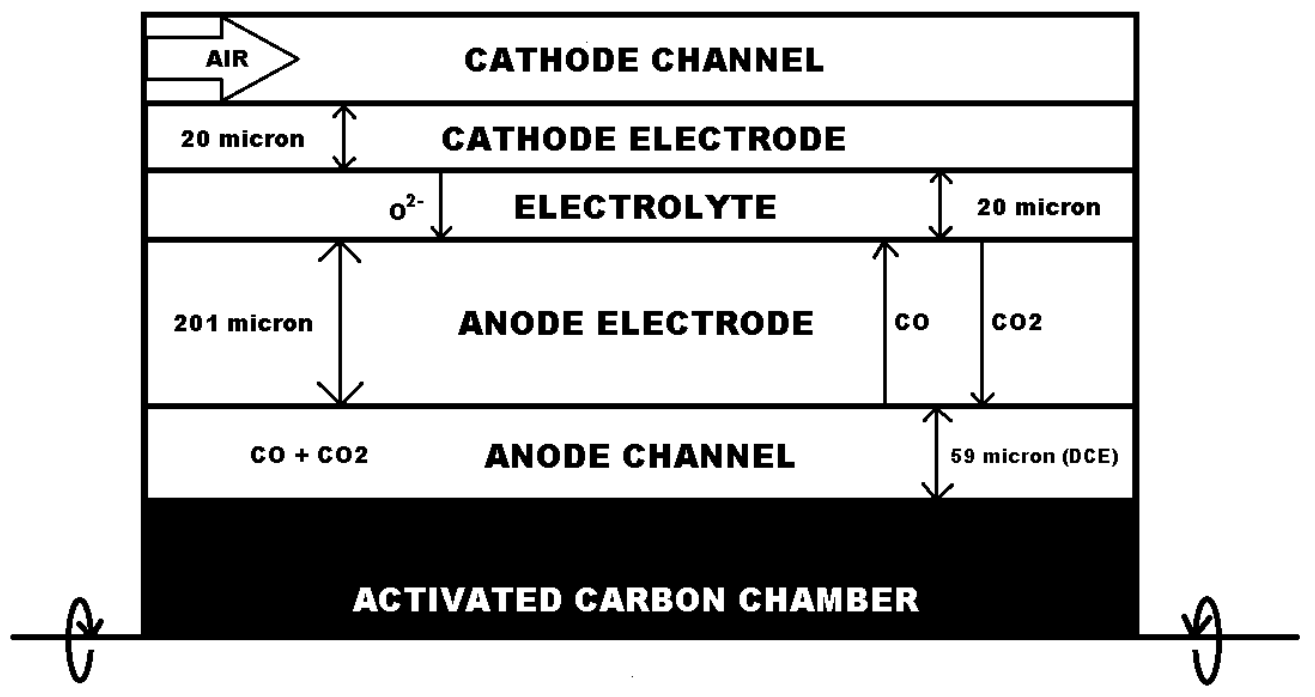

Figure 1. Schematic of anode supported DC-SOFC

The activated carbon in the anode chamber reacts with $\mathrm{CO}_{2}$ to form $\mathrm{CO}$ by the reverse Boudouard reaction:

$\mathrm{C}+\mathrm{CO}_{2} \rightarrow 2 \mathrm{CO}$

$\mathrm{CO}$ diffuses to the anode electrode (triple phase boundary) where it reacts with the oxygen anions from the cathode:

$2 \mathrm{CO}+2 \mathrm{O}^{2-} \rightarrow 2 \mathrm{CO}_{2}+4 \mathrm{e}^{-}$

At the cathode electrode, the oxygen anions are generated:

$\mathrm{O}_{2}+4 \mathrm{e}^{-} \rightarrow 2 \mathrm{O}^{2-}$ 
The thickness of the anode, electrolyte and cathode are 201, 20 and $20 \mu \mathrm{m}$ (under anode supported configuration) [1]. The tubular DC-SOFC has silver-gadolinium doped ceria composite (Ag-GDC) as the anode and cathode electrodes, and ytria-stabilized zirconia (YSZ) as the electrolyte. The main focus of our work is to study the effect of anode design parameters, namely anode porosity, anode tortuosity, anode electrode thickness, and Ag content of the anode electrode on the performance of DC-SOFC. None of the previous models have done this.

\section{Model assumptions}

a) All the gases involved in the system are assumed to be incompressible and ideal.

b) The system is assumed to be at steady state.

c) The system is assumed to operate under isothermal conditions.

d) The electrodes are assumed to be porous and the reactions are assumed to happen on the surface and across the porous anode.

e) The model assumes that reaction (2) primarily drives the electrochemical reaction and is the current generation reaction.

\section{Model equations}

2D numerical model incorporates the chemical reaction model, the electrochemical reaction model and mass transfer model. Reaction (1) is the chemical reaction which occurs in the anode chamber, and reaction (2) is the electrochemical reaction which happens at TPB of the anode electrode. From the schematic drawn in Figure 1, it can be discerned that $\mathrm{CO} / \mathrm{CO}_{2}$ flows in the anode, while air is supplied to the cathode. Oxygen molecules diffuse to the cathode where they are reduced to oxygen anions according to the reaction (3).

The oxygen ions travel through the electrolyte to TPB where they react with $\mathrm{CO}$ to form $\mathrm{CO}_{2}$ according to the reaction (2). Thus, the overall reaction can be defined as:

$$
2 \mathrm{CO}+\mathrm{O}_{2} \rightarrow 2 \mathrm{CO}_{2}
$$

\section{Actual voltage}

The difference between the thermodynamic potentials of the electrode reactions determines the reversible cell voltage, which is also known as the electromotive force (Emf). This depends on gas composition and temperature at the electrodes.

The SOFC cell potential $(E)$ can be calculated using the Nernst equation [1,2]:

$$
E=E_{0}+\frac{R T}{2 F} \ln \frac{P_{\mathrm{CO} P_{\mathrm{O}_{2}}}{ }^{0.5}}{P_{\mathrm{CO}_{2}}}
$$

where $P_{\mathrm{i}}$ is the partial pressure of component $\mathrm{i}$ and $E_{0}$ is the open circuit voltage.

For a cell, the actual voltage is always lower than the open-circuit voltage because of some internal resistances and overpotential losses.

Output voltage of SOFC can be calculated using:

$$
V=E-\eta_{\text {conc,a }}-\eta_{\text {conc,c }}-\eta_{\text {act,a }}-\eta_{\text {act,c }}-\eta_{\text {ohm }}
$$

where $\eta_{\text {conc,a }}, \eta_{\text {conc,c }}, \eta_{\text {act,a }}, \eta_{\text {act,c, }}, \eta_{\text {ohm }}$ are concentration overpotential of anode, concentration overpotential of cathode, activation overpotential of anode, activation overpotential of cathode and ohmic overpotential, respectively. 


\section{Activation overpotential}

Activation overpotential, also known as surface overpotential, is the potential difference above equilibrium potential required to overcome the activation energy of any cell reaction to generate a desired amount of current.

Activation overpotential can be calculated using [5]:

$$
\eta_{\text {act }, \mathrm{i}}=\frac{R T}{F} \sinh ^{-1}\left(\frac{J}{2 J_{\mathrm{a}, \mathrm{i}}}\right)=\frac{R T}{F} \ln \left[\frac{J}{2 J_{\mathrm{a}, \mathrm{i}}}+\sqrt{\left(\frac{J}{2 J_{\mathrm{a}, \mathrm{i}}}\right)^{2}+1}\right]
$$

where $J_{a, i}$ is electrode exchange current density of component $\mathrm{i}$.

Current density at anode and cathode can be calculated using [5]:

$$
\begin{aligned}
& J_{\mathrm{a}, \mathrm{a}}=\gamma_{\mathrm{a}} \frac{72 L_{\mathrm{G}}\left[D_{\mathrm{p}}-\left(D_{\mathrm{p}}+D_{\mathrm{s}}\right) \varepsilon\right] \varepsilon}{D_{\mathrm{s}}^{2} D_{\mathrm{p}}^{2}\left(1-\sqrt{1-L_{\mathrm{G}}^{2}}\right)} \frac{P_{\mathrm{co}}}{P_{\mathrm{ref}}} \frac{P_{\mathrm{CO}_{2}}}{P_{\text {ref }}} \exp \left(\frac{-E_{\mathrm{act}, \mathrm{a}}}{R T}\right) \\
& J_{\mathrm{a}, \mathrm{c}}=\gamma_{\mathrm{c}} \frac{72 L_{\mathrm{G}}\left[D_{\mathrm{p}}-\left(D_{\mathrm{p}}+D_{\mathrm{s}}\right) \varepsilon\right] \varepsilon}{D_{\mathrm{s}}^{2} D_{\mathrm{p}}^{2}\left(1-\sqrt{1-L_{\mathrm{G}}^{2}}\right)}\left(\frac{P_{\mathrm{O}_{2}}}{P_{\mathrm{ref}}}\right)^{0.25} \exp \left(\frac{-E_{\mathrm{act}, \mathrm{c}}}{R T}\right)
\end{aligned}
$$

where $P_{\text {ref }}$ represents reference pressure and are current densities at anode and cathode respectively, $L_{G}$ is the ratio of the grain contact neck to the grain size which is suffered by the limit of geometry and transport characteristics, $E_{\text {act }}$ is the activation energy level at the anode or cathode, $P_{\text {ref }}$ is the reference pressure, $\varepsilon$ is porosity of electrodes, while $D_{\mathrm{p}}$ and $D_{\mathrm{s}}$ are the pore size (diameter of a pore) and grain size (diameter of a grain), respectively.

\section{Concentration overpotential}

Concentration overpotential can be calculated using [1,2]:

$$
\begin{aligned}
& \eta_{\text {conc, a }}=\frac{R T}{2 F} \ln \left(\frac{P_{\mathrm{CO}} P_{\mathrm{CO}_{2}}^{\prime}}{P_{\mathrm{CO}^{1} P_{\mathrm{CO}_{2}}}^{\prime}}\right) \\
& \eta_{\text {conc, }}=\frac{R T}{4 F} \ln \left(\frac{P_{\mathrm{O}_{2}}}{P_{\mathrm{O}_{2}}^{\prime}}\right)
\end{aligned}
$$

where $P_{\mathrm{i}}$ represents partial pressure of component $\mathrm{i}$ at anode and $P_{\mathrm{i}}^{\mathrm{i}}$ represents partial pressure of component $\mathrm{i}$ at TPB.

Partial pressure can be expressed in terms of mole fractions, resulting in:

$$
\begin{aligned}
& \eta_{\text {conc, } \mathrm{a}}=\frac{R T}{2 F} \ln \left(\frac{X_{\mathrm{a}}(0) X_{\mathrm{b}}(L)}{X_{\mathrm{a}}(L) X_{\mathrm{b}}(0)}\right) \\
& X_{\mathrm{a}}(z)=\frac{X_{\mathrm{a}}(0)-\frac{\frac{1}{D_{12}^{\mathrm{e}}}+\frac{1}{D_{1 \mathrm{M}}^{\mathrm{e}}}}{\frac{1}{D^{\mathrm{e}}}+\frac{1}{D^{\mathrm{e}}}}}{1-\frac{J R T}{2 F p_{0}}\left(\frac{1}{D_{1 \mathrm{M}}^{\mathrm{e}}}+\frac{1}{D^{\mathrm{e}}}\right) z}+\frac{\frac{1}{D^{\mathrm{e}}}+\frac{1}{D_{12}^{\mathrm{e}}}}{\frac{1}{D_{1 \mathrm{M}}^{e}}+\frac{1}{D^{\mathrm{e}}}}
\end{aligned}
$$

$X_{0}(z)=1-X_{\mathrm{a}}(z)$ 
where $z$ represents anode thickness, $X_{\mathrm{a}}$ represents mole fraction of $\mathrm{CO}, X_{\mathrm{b}}$ represents mole fraction of $\mathrm{CO}_{2} . X_{\mathrm{i}}(0)$ and $X_{\mathrm{i}}(\mathrm{z})$ represent mole fraction of component $\mathrm{i}$ at anode and TPB respectively. Here, $D^{\mathrm{e}}{ }_{\mathrm{im}}$ is Knudsen coefficient and $p_{0}$ is the total pressure at anode.

Knudsen diffusion coefficient can be calculated using [9]:

$$
D^{\mathrm{e}}{ }_{\mathrm{iM}}=\left(\frac{\varepsilon d_{0}}{3 \tau}\right) D_{\mathrm{ij}} \sqrt{\frac{8 R T}{\pi \mathrm{M}_{\mathrm{i}}}}
$$

where $d_{0}$ represents diameter of pore $D_{\mathrm{ij}}$ and $M_{\mathrm{i}}$ represent effective binary diffusion coefficient and molecular weight of species $i$.

$D_{\text {ij }}$ can be calculated using [9]:

$$
D_{\mathrm{ij}}=\frac{10^{-7} T^{1.75}\left(\frac{1}{M_{\mathrm{i}}}+\frac{1}{M_{\mathrm{j}}}\right)^{1 / 2}}{P\left[\left(\sum V_{\mathrm{i}}\right)^{\frac{1}{3}}+\left(\sum V_{\mathrm{j}}\right)^{\frac{1}{3}}\right]^{2}}
$$

where $\varepsilon$ and $\tau$ corresponds to porosity and tortuosity of the medium, $P$ is represented in atm, $T$ in $\mathrm{K}, M_{\mathrm{i}}$ and $M_{\mathrm{j}}$ are the molecular weights of species $\mathrm{i}$ and $\mathrm{j}$ respectively, $\Sigma V_{\mathrm{i}}$ is the sum of the diffusion volume of component $\mathrm{i}$ and $D_{\mathrm{ij}}$ is represented in $\mathrm{m}^{2} / \mathrm{s}$.

The effective binary diffusion coefficient is related to the binary diffusion coefficient by the following equation [9]:

$$
D_{\mathrm{ij}}^{\mathrm{e}}=\left(\frac{\varepsilon}{\tau}\right) D_{\mathrm{ij}}
$$

where $\varepsilon$ and $\tau$ correspond to porosity and tortuosity of the medium.

\section{Ohmic overpotential}

The ohmic overpotential is given by:

$\eta_{\mathrm{ohm}}=j R_{\mathrm{ohm}}$

Now, $R_{\text {ohm }}$ can be represented as:

$$
R_{\text {ohm }}=\frac{\delta_{\text {anode }}}{\sigma_{\text {anode }}}+\frac{\delta_{\text {cathode }}}{\sigma_{\text {cathode }}}+\frac{\delta_{\text {elec }}}{\sigma_{\text {elec }}}
$$

where $\delta$ represents thickness and $\sigma$ represents conductivity.

\section{Results and discussion}

Figure 2 shows the performance of DC-SOFC for three different values of anode tortuosity (1,3 and 5). Tortuosity is an intrinsic property of a porous material, usually defined as the ratio of the actual flow path length to the straight distance between the ends of the flow path. Inherently, it indicates the mass transfer limitation in a given reaction (the ability of the reactant to get to the reactant surface). Figure 2 shows that DC-SOFC shows the best performance at tortuosity value of 1. The analysis of the polarization curve in Figure 2 indicates that the difference in performance among three different curves is the highest at higher current densities, indicating that mass transport limitations play a major role in the performance of DC-SOFC.

Figure 3 shows the variation of the performance of DC-SOFC with different values of anode porosity. The figure shows that the best performance is seen with anode porosity of 0.7. Again, the effect of anode porosity is seen to be the highest at high current density values, showing the effect 
of mass transport limitations on the reaction (2). The list of parameters used in these simulations is shown in Table 1.

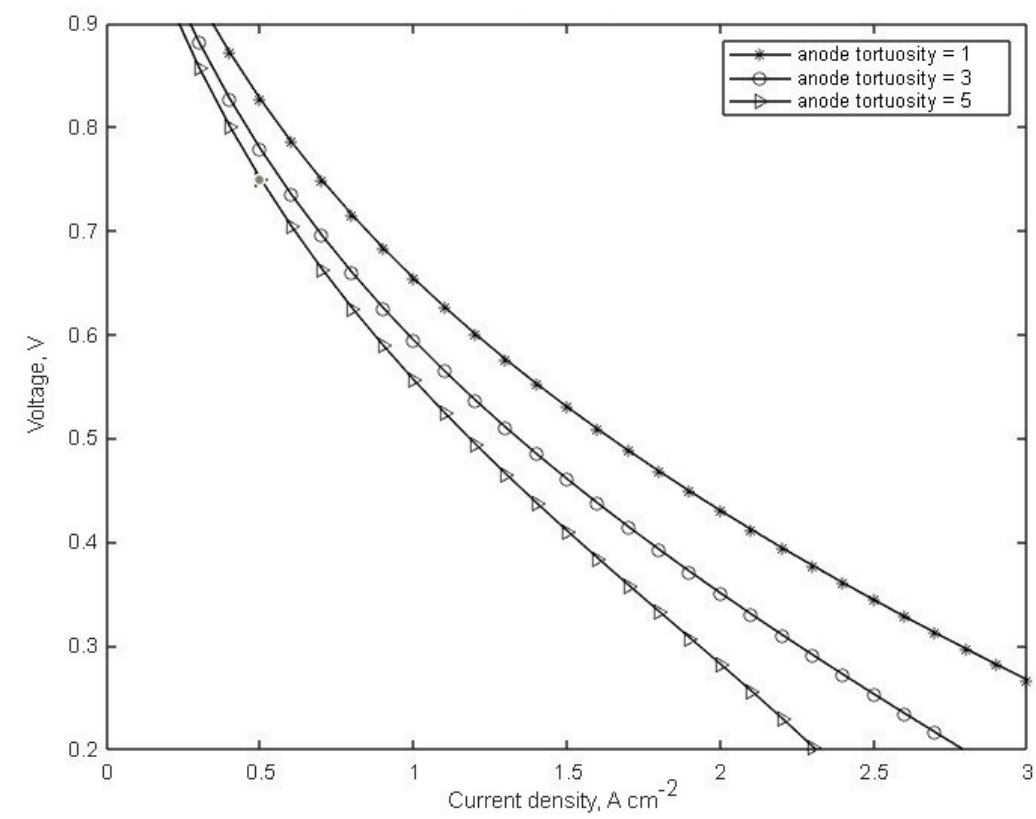

Figure 2. Performance of DC-SOFC under different anode tortuosity values

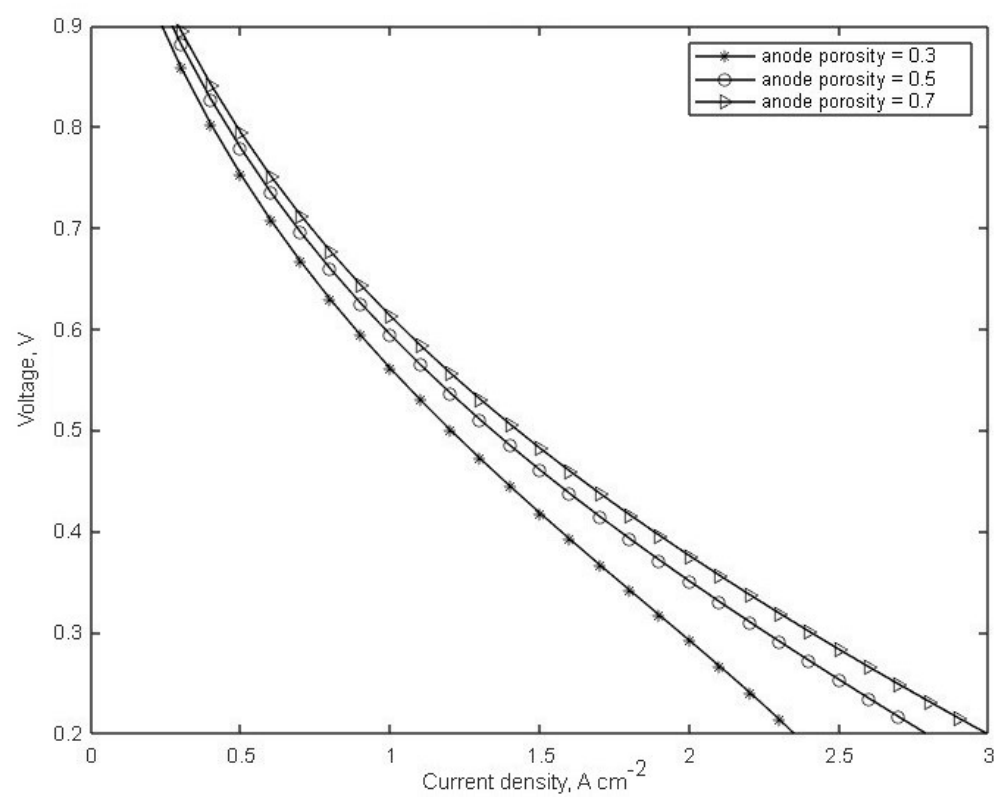

Figure 3. Performance of DC-SOFC under different anode porosity values

Figure 4 shows the effect of anode electrode thickness on the performance of DC-SOFC. The figure shows that with increasing anode electrode thickness, the performance of the DC-SOFC decreases showing the effect of ohmic resistance on the performance of DC-SOFC. Since the reactions are supposed to take place on the surface of TPB and in the interior of the anode electrode, increasing the anode electrode thickness should increase the performance of DC-SOFC owing to the increased surface area for the reaction (2). At the same time, however, the ohmic resistance generated by the thickness of the anode electrode reduces the performance of DC-SOFC, and the overall performance is seen to be reduced. 


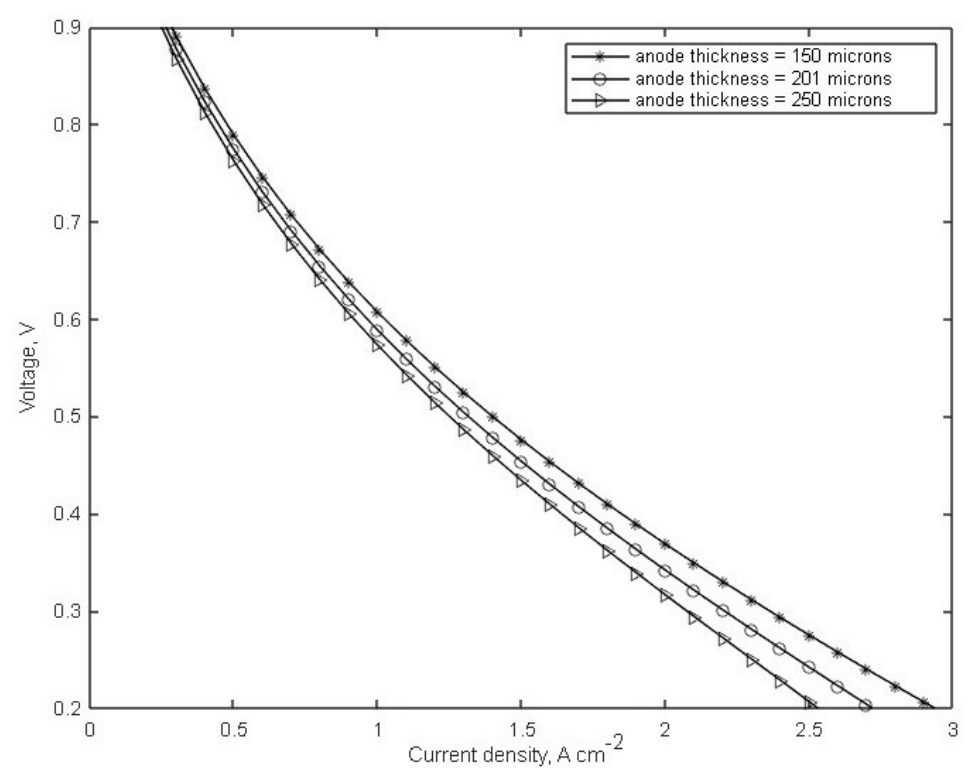

Figure 4. Performance of DC-SOFC under different anode thicknesses

Figure 5 shows the effect of the composition of the anode electrode on the performance of DCSOFC. It is seen that when the volume fraction of $\mathrm{Ag}$ in Ag-GDC composite electrode increases, the performance of DC-SOFC also increases, showing the beneficial effect of electronic conductivity of $\mathrm{Ag}$ on the performance of DC-SOFC. The electronic conductivity of Ag and ionic conductivity of GDC are key factors in determining the transport of electrons and ions through the anode electrode. $A$ higher content of $\mathrm{Ag}$ in the anode electrode makes transport of electrons through the anode electrode easier, which leads to better fuel cell performance. Figure 6 shows the effect of cell current density on the concentration profiles of $\mathrm{CO}$ and $\mathrm{CO}_{2}$ across the anode. The cell current in this case is principally determined by the reaction (2). Thus, a higher current density will indicate more reaction of $\mathrm{CO}$ and more production of carbon dioxide.

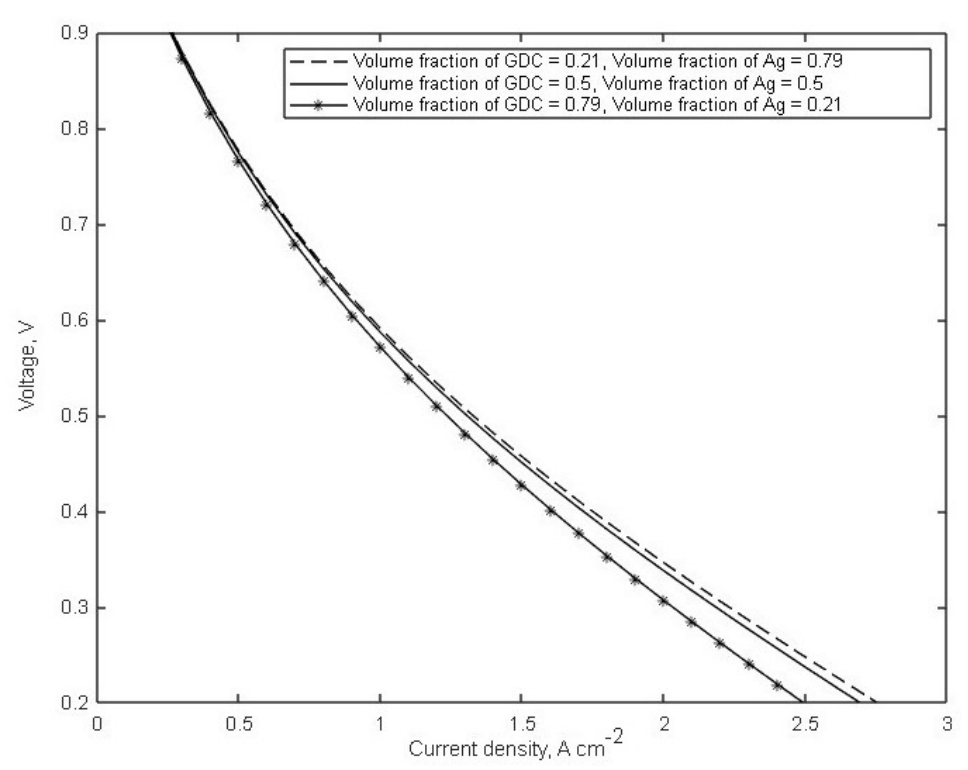

Figure 5. Performance of DC-SOFC under varying volume fractions of $\mathrm{Ag}$ in $\mathrm{Ag}$-GDC anode

Figure 6 shows that a higher concentration of $\mathrm{CO}_{2}$ and lower concentration of $\mathrm{CO}$ is seen at TPB with increasing current density (concentration profiles are shown across the anode electrode). Thus the concentration of $\mathrm{CO}$ is seen the highest at the edge of the anode electrode and the concentration of $\mathrm{CO}_{2}$ is seen to be the highest at TPB (anode electrolyte interphase). 


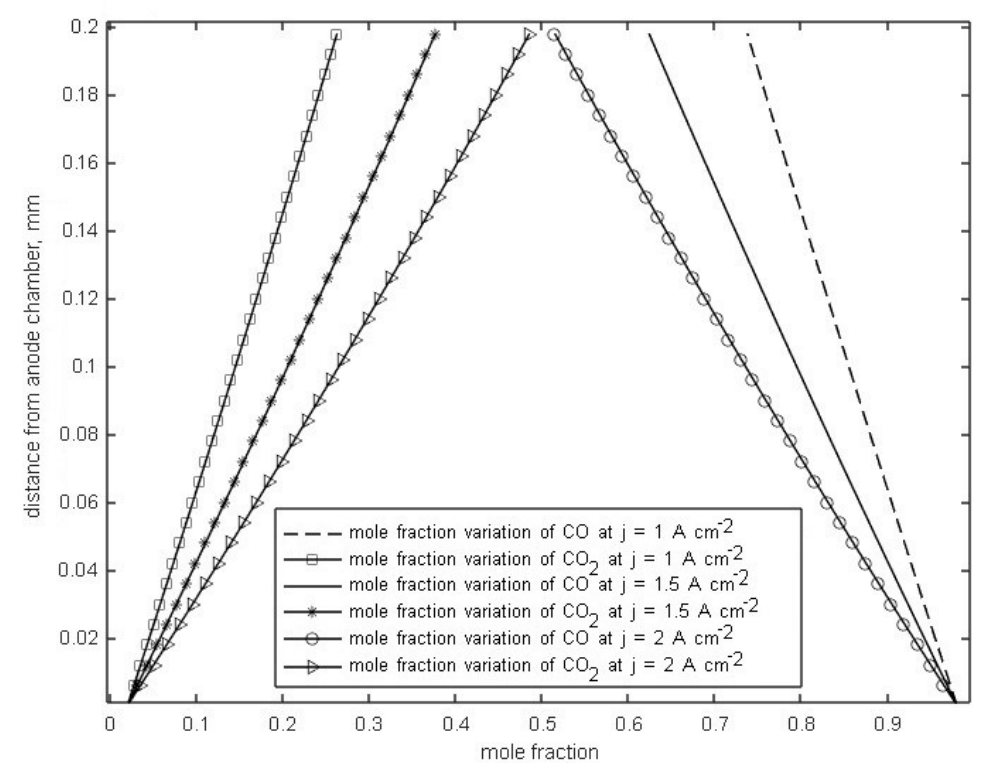

Figure 6. Concentrations profiles of gases $\left(\mathrm{CO}\right.$ and $\left.\mathrm{CO}_{2}\right)$ across the anode at varying current densities

Figures 7 and 8 show the effects of pressure and temperature on the performance of DC-SOFC. Figure 7 shows that the performance of DC-SOFC with operating pressure (1, 2 and $3 \mathrm{~atm})$. The figure shows that the performance of DC-SOFC increases with operating pressure, particularly at high current density. This indicates that a higher operating pressure facilitates the reversed Boudouard reaction kinetics producing more $\mathrm{CO}$ in the process. It also indicates that higher operating pressure facilitates mass transfer in the anode electrode. This leads to higher current density in the mass transport limited reaction. Figure 8 shows the effect of temperature on the performance of DC-SOFC. The performance is seen to increase with increasing temperature. This again is due to the faster Boudouard reaction kinetics (reverse reaction) at a higher temperature in addition to the increase in the electrochemical kinetics and the ionic conductivity of the oxygen ions through the anode electrode. An analysis of the effect of pressure and temperature on the overpotentials is given in the next section.

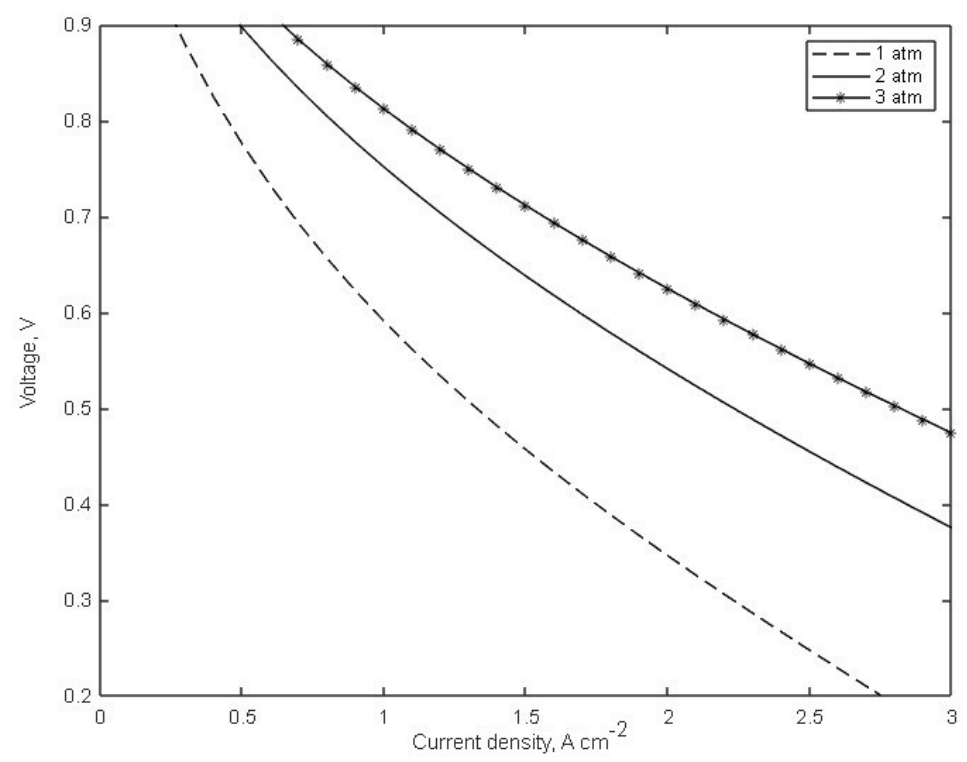

Figure 7. Performance of DC-SOFC as a function of operating pressure 


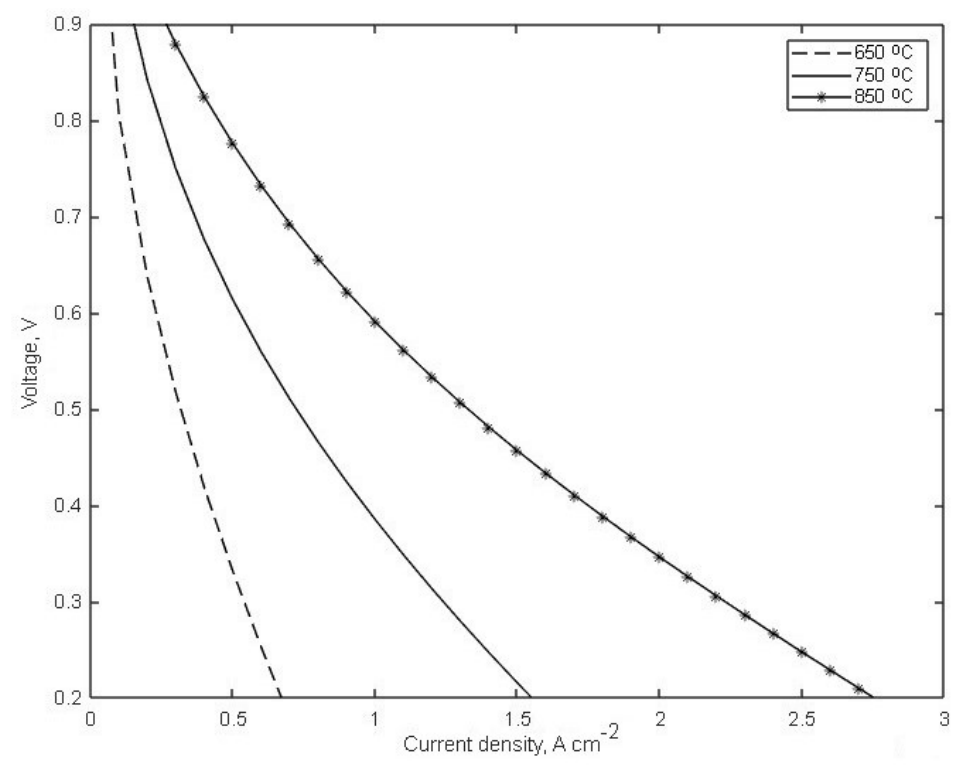

Figure 8. Performance of DC-SOFC as a function of operating temperature

\section{Effect of operating parameters on overpotentials}

\section{Activation overpotential}

Inherently the activation overpotential indicates the resistance to the kinetics of the reaction taking place on the electrodes. The activation overpotential is derived from the Butler-Volmer equation. The values of the activation overpotential depends on several factors like operating pressure, temperature, gas composition, electrode porosity, etc. Figures $9 \mathrm{a}$ and $9 \mathrm{~b}$ indicate the effect of temperature and operating pressure on the activation overpotential for the reaction (2) occurring within the anode electrode. Figure 9a shows that temperature has a significant effect on the activation overpotential. The activation overpotential (resistance to the kinetics of the reaction) is the lowest at the temperature of $850{ }^{\circ} \mathrm{C}$, showing the effect of temperature on the reversed Boudouard reaction (1) (chemical reaction) and reaction (2) (electrochemical reaction). Figure $9 \mathrm{~b}$ shows the effect of pressure on the activation overpotential. The figure shows that an increasing pressure supports an increasing reaction rate both for the reversed Boudouard reaction (1) and reaction (2).

a

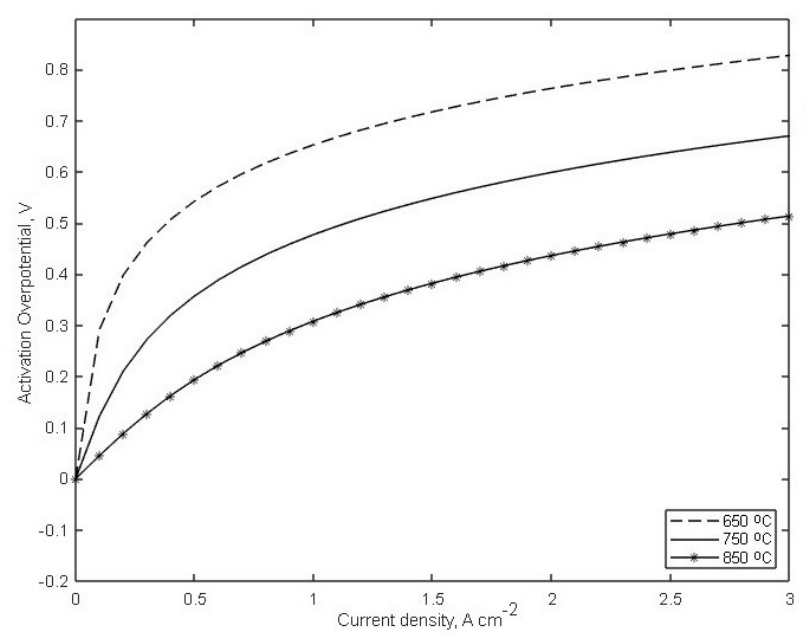

b

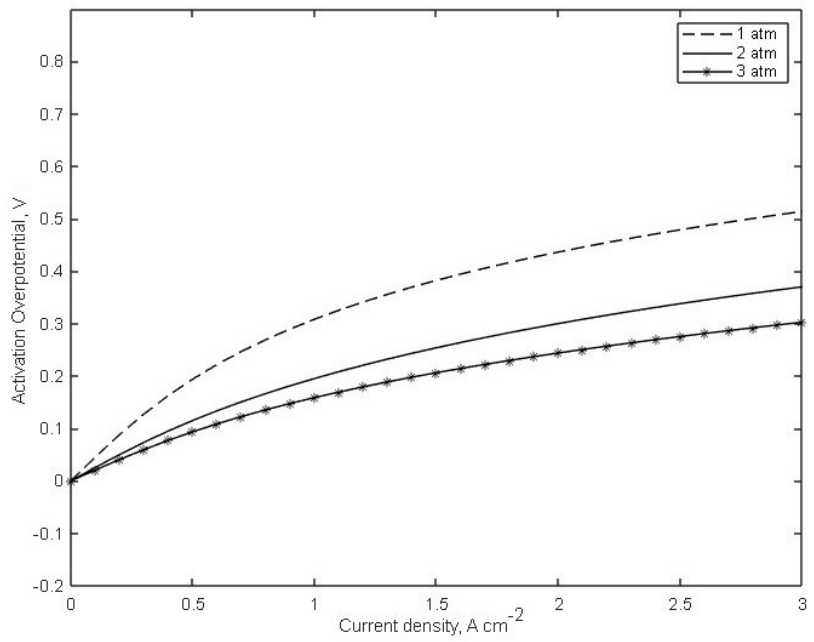

Figure 9. Activation overpotential vs. current density for $\boldsymbol{a}$ - various temperatures;

$\boldsymbol{b}$ - various pressures 


\section{Concentration overpotential}

The concentration overpotential is caused by the resistance to the transport of reactant species approaching TPB and the product species leaving TPB. Figures 10a and 10b show the effect of temperature and pressure on the concentration overpotential. Figure 10a shows that with increasing temperature, the resistance to transport of species to and away from TPB decreases, showing the effect of diffusion (diffusion increases with increasing temperature). Thus, we see that the concentration overpotential is the lowest at $850^{\circ} \mathrm{C}$. Figure $10 \mathrm{~b}$ shows that increasing pressure conditions reduces the concentration overpotential required for the reactions. It shows that at 3 atm, the resistance to the mass transport of the reactant and product species is the lowest, showing the effect of pressure on the diffusion, i.e., mass transport of the species. However, the effect of temperature and pressure on the concentration overpotential seems to be less significant than for the activation overpotential.

a

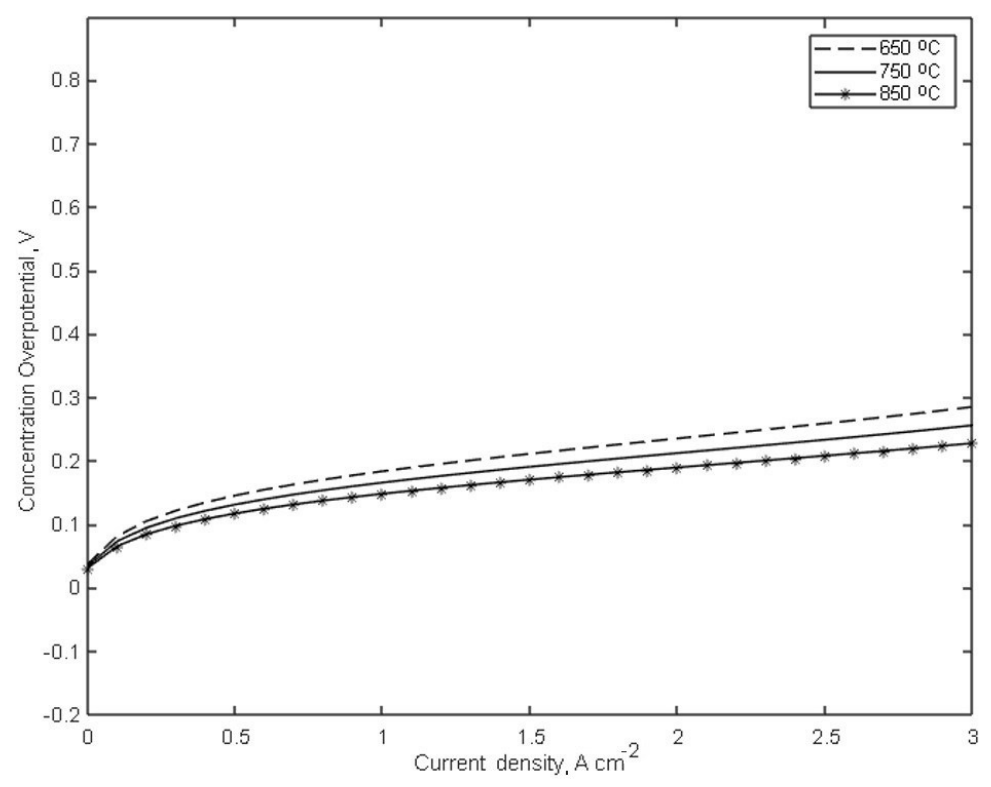

b

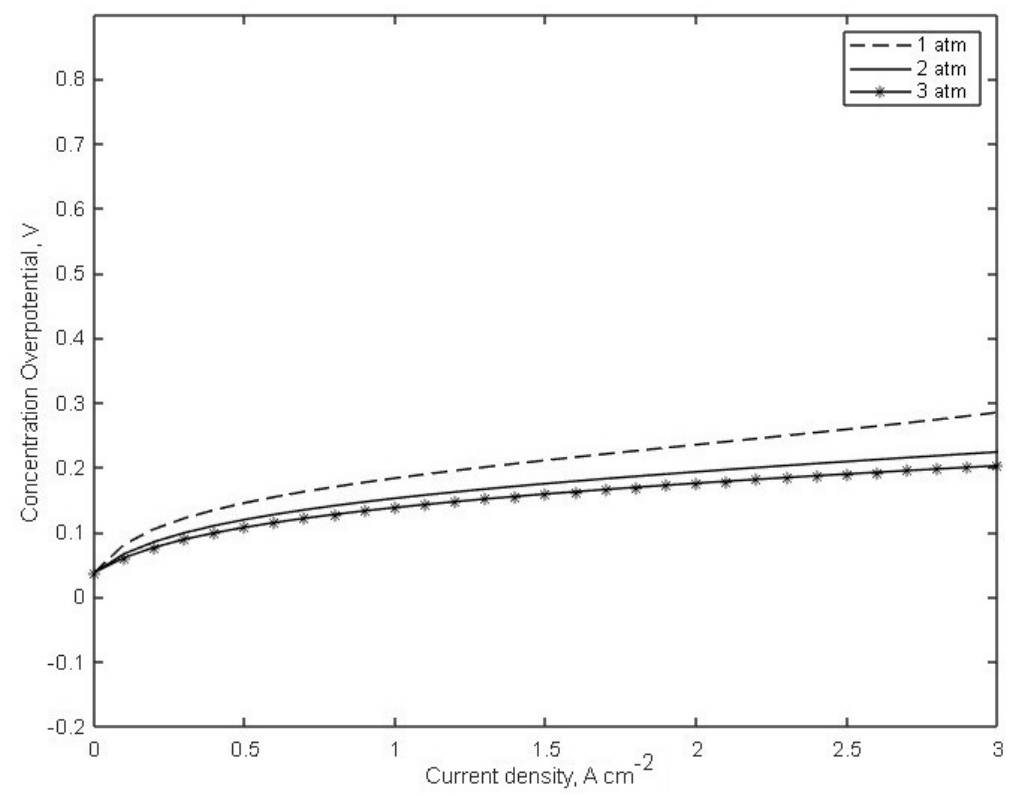

Figure 10. Concentration overpotential vs. current density for $\boldsymbol{a}$ - various temperatures;

$\boldsymbol{b}$-various operating pressures 
Ohmic overpotential

The ohmic overpotential is mainly caused by the resistance to conduction of ions through the electrolyte and electrons through the electrodes. The conductivity of the electrolyte is usually a function of the operating temperature. Figure 11 shows that the operating temperature plays a major role in reducing the ohmic overpotential in the system. The least resistance to the transport of ions through the anode electrode is seen at a temperature of $850^{\circ} \mathrm{C}$. The temperature is seen to play a significant role in reducing the resistance to the conduction of ions through the electrolyte and electrodes.

Figure 12 shows the comparison of simulation results with experimental data [5]. The parameters used for simulations of curves in Figure 12 are shown in Table 2. Simulation results presented in Figure 12 are found to compare very well with experimental data.

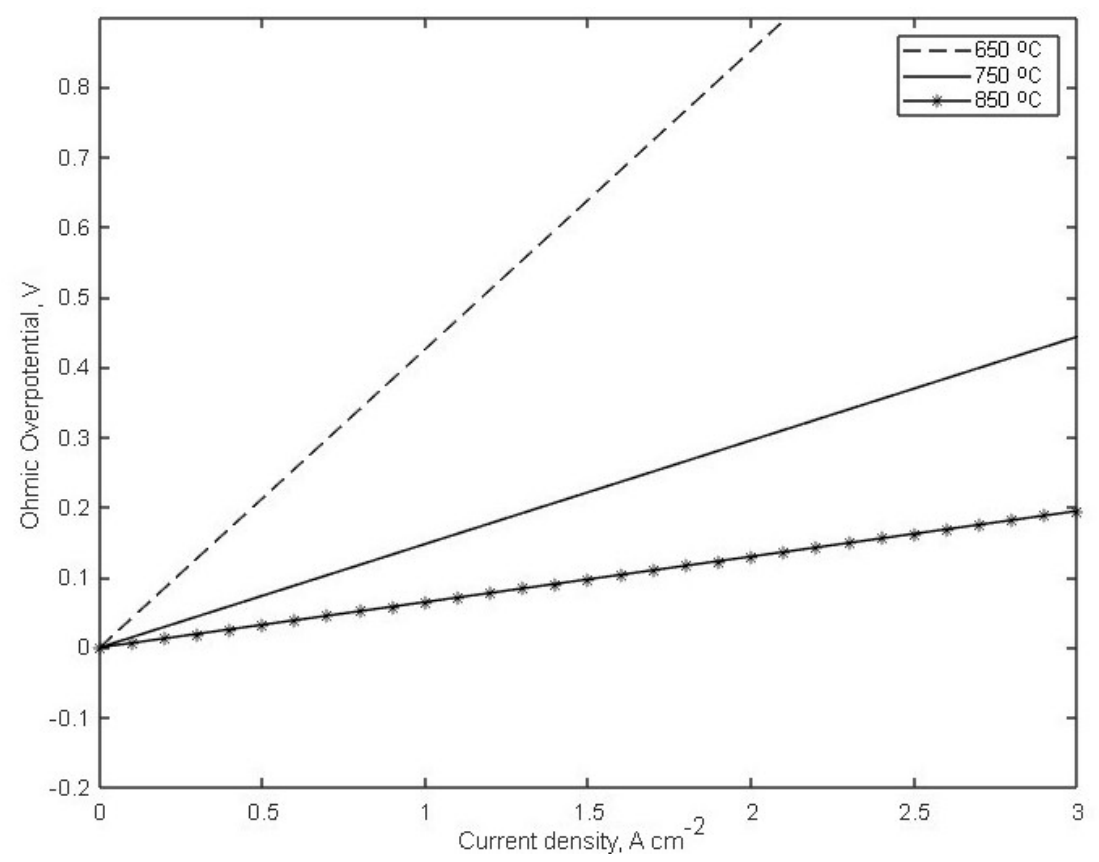

Figure 11. Ohmic overpotential vs. current density for various temperatures

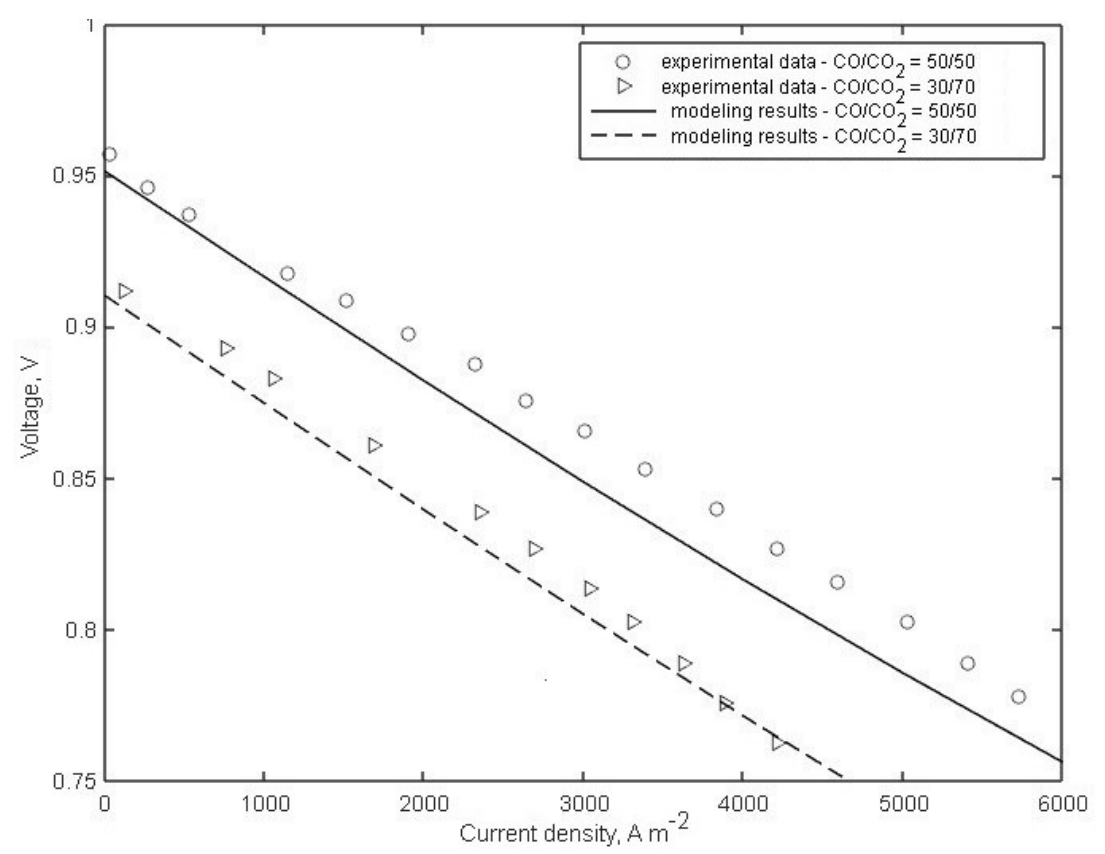

Figure 12. Comparison of modeling predictions with experimental data [5] 
Table 1. Model parameters used for calculations of graphs presented in Figures 2-10 [1].

\begin{tabular}{|c|c|}
\hline Parameter & Value \\
\hline Cathode tortuosity & 3 \\
\hline Anode tortuosity & 3 \\
\hline $\mathrm{O}_{2}$ exchange current density $\left(i_{\mathrm{O}_{2}}\right), \mathrm{A} \mathrm{m}^{-2}$ & 2000 \\
\hline CO exchange current density $\left(i_{\mathrm{CO}}\right), \mathrm{A} \mathrm{m}^{-2}$ & 2250 \\
\hline CO charge transfer coefficient $\left(\alpha_{\mathrm{CO}}\right)$ & 0.5 \\
\hline $\mathrm{O}_{2}$ charge transfer coefficient $\left(\alpha_{\mathrm{O}_{2}}\right)$ & 0.5 \\
\hline Pressure in anode chamber, atm & 1 \\
\hline Distance between anode chamber and electrode, $\mu \mathrm{m}$ & 59 \\
\hline Pressure in cathode chamber, atm & 1 \\
\hline Cathode gas composition & Air \\
\hline Temperature, $\mathrm{K}$ & 1123 \\
\hline Diameter of pore, $\mu \mathrm{m}$ & 1 \\
\hline Ionic conductivity of GDC, $\mathrm{S} \mathrm{m}^{-1}$ & $\frac{100}{T} 10^{6.66071-\frac{5322.92}{T}}$ \\
\hline Ionic conductivity of YSZ, $\mathrm{S} \mathrm{m}^{-1}$ & $3.3410^{4} e^{\frac{-10300}{T}}$ \\
\hline Electronic conductivity of $\mathrm{Ag}, \mathrm{S} \mathrm{m}^{-1}$ & $\frac{1.59 e^{8}}{0.0038 T-0.1134}$ \\
\hline Porosity of cathode & 0.46 \\
\hline Porosity of anode & 0.46 \\
\hline Electrode volume fraction of GDC & 0.21 \\
\hline Electrode volume fraction of $\mathrm{Ag}$ & 0.79 \\
\hline
\end{tabular}

Table 2. Model parameters for model and experimental [5] fits shown in Figure 12.

\begin{tabular}{|c|c|}
\hline Parameter & Value \\
\hline Cathode tortuosity & 5.4 \\
\hline Anode tortuosity & 5.4 \\
\hline $\mathrm{O}_{2}$ exchange current density $\left(i_{\mathrm{O}_{2}}\right), \mathrm{A} \mathrm{m}^{-2}$ & 3640 \\
\hline CO exchange current density $\left(i_{c o}\right), \mathrm{A} \mathrm{m}^{-2}$ & 3492 \\
\hline CO charge transfer coefficient $\left(\alpha_{\mathrm{CO}}\right)$ & 0.5 \\
\hline $\mathrm{O}_{2}$ charge transfer coefficient $\left(\alpha_{\mathrm{O}_{2}}\right)$ & 0.5 \\
\hline Pressure in anode chamber, atm & 1 \\
\hline Pressure in cathode chamber, atm & 1 \\
\hline Cathode gas composition & Air \\
\hline Temperature, $\mathrm{K}$ & 1123 \\
\hline Diameter of pore, $\mu \mathrm{m}$ & 3 \\
\hline Ionic conductivity of YSZ, $\mathrm{S} \mathrm{m}^{-1}$ & $3.3410^{4} e^{\frac{-10300}{T}}$ \\
\hline Electronic conductivity of cathode, $\mathrm{S} \mathrm{m}^{-1}$ & $8.410^{3}$ \\
\hline Electronic conductivity of anode, $\mathrm{S} \mathrm{m}^{-1}$ & $8.010^{3}$ \\
\hline Porosity of cathode & 0.48 \\
\hline Porosity of anode & 0.48 \\
\hline Electrode volume fraction of GDC & 0.21 \\
\hline Electrode volume fraction of $\mathrm{Ni}-\mathrm{YSZ}$ & 0.5 \\
\hline Electrode volume fraction of YSZ-LSM & 0.5 \\
\hline
\end{tabular}




\section{Conclusions}

A mathematical model is developed to study the performance (displayed as cell polarization curve) of a carbon assisted solid oxide fuel cell (DC-SOFC). The model postulates that different anode design parameters, i.e. anode porosity, anode tortuosity, anode electrode thickness and Ag concentration in the anode electrode play a key role in the performance of DC-SOFC. The effect of operational pressure and temperature on the activation, concentration and ohmic overpotentials is studied. The temperature and pressure are found to have a significant impact on the activation and concentration overpotentials. Ohmic overpotential is found to be affected significantly by temperature. Model results are compared with experimental data taken from the literature and found to compare well.

\section{Nomenclature}

\begin{tabular}{|c|c|}
\hline$V / \mathrm{V}$ & Operating potential \\
\hline$E / \mathrm{V}$ & Equilibrium Nernst potential \\
\hline$E_{0} / \mathrm{V}$ & Standard potential \\
\hline$R=8.314 \mathrm{~J} \mathrm{~mol}^{-1} \mathrm{~K}^{-1}$ & Universal gas constant \\
\hline$T / \mathrm{K}$ & Temperature \\
\hline$F=96,485 \mathrm{C} \mathrm{mol}^{-1}$ & Faraday constant \\
\hline$P_{\mathrm{i}} /$ atm & Bulk partial pressure of species \\
\hline$P_{\mathrm{i}}^{\mathrm{l}} / \mathrm{atm}$ & L ocal partial pressure of species i at TPB \\
\hline TPB & Triple phase boundary \\
\hline$x_{\mathrm{i}}$ & Mole fraction of species i \\
\hline$D^{\mathrm{e}} \mathrm{ij}_{1} / \mathrm{m}^{2} \mathrm{~s}^{-1}$ & Effective binary diffusion coefficient \\
\hline$D^{\mathrm{e}}{ }_{\mathrm{iM}} / \mathrm{m}^{2} \mathrm{~s}^{-1}$ & Knudsen coefficient \\
\hline$P_{0}$ or $P /$ atm & Total pressure at anode \\
\hline$P_{\text {ref }}$ & Reference pressure \\
\hline $\mathrm{M}_{\mathrm{i}} / \mathrm{kg} \mathrm{kmol}^{-1}$ & Molecular weight of species i \\
\hline$d_{\mathrm{o}} / \mathrm{m}$ & Diameter of pore \\
\hline$P_{c} /$ atm & Operating pressure at cathode \\
\hline$V_{\mathrm{i}}$ & Diffusion volume of component i \\
\hline$j / \mathrm{A} \mathrm{m}^{-2}$ & Current density \\
\hline$j_{0, a / c} / A^{-2}$ & Exchange current density at i (anode/cathode) \\
\hline$R_{\text {ohm }} / \Omega$ & Internal resistance of the cell \\
\hline$L$ & Ratio of the length of the grain contact neck to the grain size \\
\hline$E_{\mathrm{act}, \mathrm{a}} / \mathrm{J} \mathrm{mol}^{-1}$ & Activation energy of anode \\
\hline$E_{\mathrm{act}, \mathrm{c}} / \mathrm{J} \mathrm{mol}^{-1}$ & Activation energy of cathode \\
\hline$D_{\mathrm{s}} / \mathrm{m}$ & Grain size \\
\hline
\end{tabular}

Greek letters

$\begin{array}{ll}\varepsilon & \text { Porosity of medium } \\ \tau & \text { Tortuosity of medium } \\ \eta_{\text {conc,a }} / \mathrm{V} & \text { Anode concentration potential } \\ \eta_{\text {conc,c }} / \mathrm{V} & \text { Cathode concentration potential } \\ \eta_{\text {act,a }} / \mathrm{V} & \text { Anode activation potential } \\ \eta_{\text {act,c }} / \mathrm{V} & \text { Cathode activation potential } \\ \eta_{\text {ohm }} / \mathrm{V} & \text { Ohmic overpotential } \\ \delta_{\text {anode }} / \mathrm{m} & \text { Anode thickness } \\ \delta_{\text {cathiode }} / \mathrm{m} & \text { Cathode thickness } \\ \delta_{\text {elec }} / \mathrm{m} & \text { Electrolyte thickness } \\ \sigma_{\mathrm{i}} / \mathrm{S} \mathrm{m} \mathrm{m}^{-1} & \text { Conductivity at i (anode/cathode/electrolyte) } \\ \gamma_{\mathrm{a}} / \mathrm{A} \mathrm{m} & \text { Coefficient for exchange current density of anode } \\ \gamma_{\mathrm{c}} / \mathrm{A} \mathrm{m} & \text { Coefficient for exchange current density of cathode } \\ \delta_{\text {anode }} / \mathrm{m} & \text { Anode thickness } \\ \delta_{\text {cathode }} / \mathrm{m} & \text { Cathode thickness }\end{array}$


Acknowledgement: The authors would like to thank BITS Pilani, Hyderabad for support in writing this article.

\section{References}

[1] H. Xu, B. Chen, J. Liu, N. Meng, Applied Energy 178 (2016) 353-362 https://doi.org/10.1016/j.apenergy.2016.06.064.

[2] H. Xu, B. Chen, H. Zhang, P. Tan, G. Yang, J. Irvine, N. Meng, Journal of Power Sources 382 (2018) 135-143 https://doi.org/10.1016/i.jpowsour.2018.02.033.

[3] Z. Yang, H. Xu, B. Chen, P. Tan, H. Zhang, N. Meng, Energy Conversion and Management 171 (2018) 279-286 https://doi.org/10.1016/j.enconman.2018.05.100.

[4] H. Xu, B. Chen, H. Zhang, Q. Sun, G. Yang, N. Meng, International Journal of Hydrogen Energy 42 (2017) 15641-15651 https://doi.org/10.1016/i.ijhydene.2017.05.075.

[5] H. Zhang, J. Chen, J. Zhang, International Journal of Hydrogen Energy 38 (2013) 7947-7954 https://doi.org/10.1016/j.ijhydene.2013.04.107.

[6] Y. Bai, Y. Liu, Y. Tang, Y. Xie, J. Liu, International Journal of Hydrogen Energy 36 (2011) 9189-9194 https://doi.org/10.1016/i.ijhydene.2011.04.171.

[7] B. R. Alexander, R. E. Mitchell, T. M. Gür, Journal of the Electrochemical Society 158 (2011) B505B513 https://doi.org/10.1149/1.3560475.

[8] B. R. Alexander, R. E. Mitchell, T. M. Gür, Journal of the Electrochemical Society 159 (2012) F810F814 https://doi.org/10.1149/1.3560475.

[9] S. K. Das, Journal of Electrochemical Energy Conversion and Storage 17 (2020) 031017 https://doi.org/10.1149/2.032212jes.

[10] R. Sanjeev, G. Sakthi, B. Krishnamurthy, lonics 27 (2020) 729-741 https://doi.org/10.1007/s11581020-03834-9.

(C)2021 by the authors; licensee IAPC, Zagreb, Croatia. This article is an open-access article distributed under the terms and conditions of the Creative Commons Attribution license (https://creativecommons.org/licenses/by/4.0/) 